\title{
Transatlantica
}

Revue d'études américaines. American Studies Journal

$1 \mid 2012$

Le roman policier, littérature transatlantique / Maisons

Hantées

\section{«Lunch Atop a Skyscraper » : le cliché mythique fête ses 80 ans}

Frédéric Perrier

\section{(2) OpenEdition}

Journals

Édition électronique

URL : https://journals.openedition.org/transatlantica/5788

DOI : 10.4000/transatlantica.5788

ISSN : 1765-2766

Éditeur

Association française d'Etudes Américaines (AFEA)

Référence électronique

Frédéric Perrier, « "Lunch Atop a Skyscraper » : le cliché mythique fête ses 80 ans », Transatlantica [En ligne], 1 | 2012, mis en ligne le 13 novembre 2012, consulté le 01 février 2023. URL : http://

journals.openedition.org/transatlantica/5788; DOI : https://doi.org/10.4000/transatlantica.5788

Ce document a été généré automatiquement le 1 février 2023.

\section{(c) $(1) \odot$}

Creative Commons - Attribution - Pas d'Utilisation Commerciale - Pas de Modification 4.0 International - CC BY-NC-ND 4.0

https://creativecommons.org/licenses/by-nc-nd/4.0/ 


\title{
"Lunch Atop a Skyscraper »: le cliché mythique fête ses 80 ans
}

\author{
Frédéric Perrier
}

1 Le très célèbre cliché "Lunch Atop a Skycraper " a fêté ses 80 ans le 20 septembre dernier. On y voit onze ouvriers, pendant leur pause déjeuner, assis sur une poutre

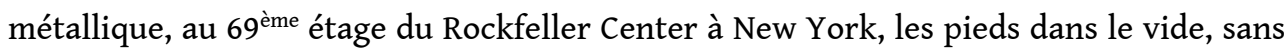
aucune sécurité. C'est l'image la plus vendue de l'agence fondée en 1989 par Bill Gates, Corbis Image, qui, pour l'occasion, a fait de surprenantes révélations.

2 L'archiviste de Corbis, Ken Johnston, a indiqué sur le blog du Wall Street Journal, Metropolis, que ce cliché était en fait une publicité pour le Rockfeller Center destinée à être diffusée auprès des agences de presse « as a celebration of the idea of Rockefeller Center being built ». Il ajoute toutefois que les hommes photographiés étaient bel et bien des ouvriers.

3 Mais d'autres mystères subsistent, notamment sur l'identité du photographe. Officiellement attribuée à Charles C. Ebbets (1905-1978) en 2003, cette photographie avait circulé auparavant avec la mention "auteur inconnu», à laquelle Corbis est aujourd'hui revenue, comme l'indique son site. Par ailleurs, malgré les efforts de l'agence qui, en 2000, avait engagé des détectives privés et fait paraître des annonces dans la presse new yorkaise pour retrouver l'identité des ouvriers, le nom de ces hommes devenus célèbres reste à ce jour inconnu. Dans un article publié le 20 septembre 2012 dans The Independent, Johnston déclarait: «For most of the men on the beam we got multiple names and for some no names at all. Because it was so mixed up and impossible to cross-reference we thought it could not be solved ».

4 Johnston souligne enfin que le caractère exceptionnel de ce cliché tient à ce qu'il exalte de force et d'espérance au cœur de la Dépression: « Usually when you saw lines of men, at that time, they'd be in a bread line, at a soup kitchen, not working and eating lunch. Here, in the new and exciting age of skyscrapers, the photo displayed the worker in America in the 30s, keeping going and building ".

5 Il faut aussi signaler un site fort riche, «Lunch in the Sky », créé spécialement pour l'événement par l'agence Corbis, où l'on trouve toutes les informations relatives à ce 
cliché, mais aussi sur le contexte dans lequel il a été pris, dans les domaines de la politique, des transports, de l'architecture ou encore de la mode sur un air de musique des années 1930 des plus entraînants.

INDEX

Thèmes : Trans'Arts 